\title{
Identification of bacteria from blood and joint fluids of human subjects as Bacillus licheniformis
}

\author{
PHYLLIS PEASE \\ Department of Bacteriology, University of Birmingham, Birmingham B15 2TJ
}

In previous papers, the occurrence of an L-form of a Gram-positive bacterium resembling Listeria, in the blood and joint fluids of arthritic, and the blood of normal persons, was reported (Pease, 1967, $1969,1970 \mathrm{a}, \mathrm{b})$. Although similar organisms have been described from this source in the past, a satisfactory bacteriological description has been lacking, in most cases, and the purpose of this paper is to provide such a description. The organism is, in fact, identifiable as the L-form of Bacillus licheniformis, which has previously been found in association with arthritic conditions of poultry (Roberts, 1964) and probably of man (Benedek, 1955).

\section{Methods}

\section{ORGANISMS}

Seventy strains of bacteria were examined, representing those isolated from 170 out of 176 cases of rheumatoid arthritis, by the techniques described below. For comparison, three type strains of Listeria monocytogenes (NCTC 5214, 5348, 10357); one each of Bacillus licheniformis (NCTC 10341) and B. licheniformis var. lentus (NCTC 4824) were examined. The synovial fluid isolates of Duthie, Stewart, Alexander, and Dayhoff (1967), and a strain of the bacterium isolated by Alexander-Jackson (1954) were also investigated. Twelve newly isolated strains of $\boldsymbol{B}$. licheniformis, from this laboratory and elsewhere, were examined physiologically for comparison; and all 21 types species of Bacillus (excl. B. anthracis) available from the NCTC, were compared serologically.

\section{CULTURE}

The original cultures were made by adding $2 \mathrm{ml}$. serum, whole blood, or joint fluid to $15 \mathrm{ml}$. of Brewer's medium in a McCartney screw-capped bottle, and incubating at $37^{\circ} \mathrm{C}$. until slight visible turbidity could be detected with the naked eye, which was usually after 2 to 6 weeks. Subcultures were made on nutrient agar (Oxoid Blood-agar base No. 2, or BBL Trypticase Soy). Numerous cultural controls against contamination were included. These are listed in Pease (1969). The growth was concentrated by centrifugation at 2,500 r.p.m., and resuspended in $1 \mathrm{ml}$. sterile distilled water for examination. For phase-contrast microscopy, a few drops were mounted between slide and coverslip and sealed at the edges with beeswax. These were examined with a Wild $\times 50$ phase-contrast lens and condenser. In some cases, the serum or fluid was examined directly by these means, without prior culturing.

Physiological tests were performed on the bacterial phase, mainly according to the methods of Cowan and Steel (1965), all at $37^{\circ} \mathrm{C}$. and with the following details or modifications. In the starch-hydrolysis test, Lugol's iodine was used, and in the Indole test, Kovac's reagent. For the gelatin liquefaction test, Cowan and Steel's Method 2 was used. Slopes inoculated from heavy growth on nutrient agar were used for the citrate utilization test. Slopes of ammonium salt sugars, sterilized by filtration, were used in the tests for acid from carbohydrates. In the casein hydrolysis test, Oxoid Skim Milk powder (10 per cent.) was used in place of skim milk, and sterilization was at $121^{\circ} \mathrm{C}$. for $5 \mathrm{~min}$.

\section{ANTIGENIC ANALYSIS}

The organisms were grown on BBL Trypticase Soy agar plates for $18 \mathrm{hrs}$. Antigens for gel-diffusion tests were prepared against all the strains listed, from heavy, heatkilled, washed suspensions of bacteria in 0.2 per cent. (v/v) formol saline, and ultrasonically disintegrated.

Antisera were prepared in rabbits against all three strains of Listeria monocytogenes and four strains of new isolates, by giving two subcutaneous injections of $1 \mathrm{ml}$. of ultrasonically disintegrated antigen plus $1 \mathrm{ml}$. of Freund's adjuvant (Bacto) at an interval of 14 days. After a further 2 weeks, a series of subcutaneous injections of $1 \mathrm{ml}$. of the antigen alone was given on ten occasions over 3 weeks. This procedure was usually sufficient to produce antisera capable of giving rise to strong lines of precipitation in gel-diffusion tests set up against homologous antigens.

\section{Results}

Primary cultures in fluid medium were clearly visible after 2 to 6 weeks' incubation, previous to which, no sign of growth appeared. Typically, they showed as a turbidity of the medium, that was readily seen by phase-contrast microscopy to consist of budding spheroplasts, as described by Pease (1969). When these cultures were subcultured on nutrient agar, the bacillary phase could be obtained from any L-phase culture that showed turbidity at about 6 weeks' incubation. A loopful of fluid culture, plated on solid medium, produced a profuse growth of very 
small, pale, translucent colonies, composed of asporogenous, Gram-positive, occasionally acid-fast rods, morphologically resembling Listeria (with which, in view of their antigenic reactions, see below, they had provisionally been identified). On subculture, over a period of several weeks, these cultures gradually assumed the very characteristic appearance of Bacillus licheniformis colonies.

The earlier cultures seldom or never bore visible endospores, but latterly these became common, as the typical morphology was progressively restored.

\section{PHYSIOLOGY}

The results of physiological tests on fifteen of the new, human isolates and the twelve saprophytes are shown in the Table, by comparison with type Bacillus licheniformis and Alexander-Jackson's isolate. Most of the human isolates and all the saprophytes were identical with the type strain, or varied only slightly, by the criteria employed, but two of the former were weak fermenters, and rather resembled the inactive, $B$. lentus, variant.

\section{ANTIGENIC ANALYSIS}

Antigens prepared from all the strains of Listeria and Bacillus listed under 'Methods', the isolates of Duthie and others (1967), the organism of AlexanderJackson, and seventy new human isolates were tested by the gel-diffusion precipitin reaction against the sera prepared from three strains of Listeria and four strains of new isolates. Tests were performed with these antigens and sera in all possible combinations. All seventy antigens from new isolates, AlexanderJackson's organism, and B. licheniformis var. lentus reacted positively with the antisera against new isolates, giving strong multiple lines of precipitation. The other NCTC species of Bacillus gave occasional, weak, and variable lines. The isolates of Duthie and others (1967) appeared to be serologically unrelated.
The antiserum produced against Listeria strain 5214 gave a strong reaction against all seventy new isolates. The remaining two Listeria antisera did not produce lines of precipitation against the new isolates, but the presence of common antigens was detectable in all these by the continuity of lines when their antigens were placed in cups, alternating with the antigens of the new isolates, surrounding Listeria (5214) serum.

\section{Discussion}

The evidence, in this paper, suggests that the blood of many human beings is infected with L-forms of Bacillus licheniformis, which can be isolated in fluid culture (but only after very prolonged incubation) in the form of spheroplasts. This is surprising at first encounter, but not without support from other sources. This organism is transformed, after subculture on solid medium into a Gram-positive rod, resembling Listeria or a 'diphtheroid', or even an acid-fast bacillus, with all of which it seems to have been confused in the past. My previous tentative identification of this asporogenous phase of culture as 'Listeria-like' (Pease, 1967) was based both on morphology and on antigenic analysis, and it has since been shown that there is a true antigenic relationship between $L$. monocytogenes and $B$. licheniformis that is not caused by the non-specific Rantz antigen (Pease, Nicholls, and Stuart, 1972). Also, B. licheniformis, which is very small for a Bacillus species (c. $1 \mu$ in diameter), exists in two morphologically distinct phases in ordinary pure cultures, and in one of these the bacilli are asporogenous (Bisset and Street, 1973). This leaves little doubt that the organisms now isolated, while bearing some resemblance to Listeria, are identifiable as B. licheniformis or variants of it, on morphological, biochemical, and serological grounds. The same

Table Physiological tests

\begin{tabular}{|c|c|c|c|c|c|c|}
\hline \multirow[t]{2}{*}{ Characteristics } & Arthritis isolates & \multirow{2}{*}{$\begin{array}{l}\text { Alexander- } \\
\text { Jackson's } \\
\text { isolates }\end{array}$} & \multirow{2}{*}{$\begin{array}{l}\text { Four strains } \\
\text { isolated from } \\
\text { vicinity }\end{array}$} & \multirow{2}{*}{$\begin{array}{l}\text { Eight strains } \\
\text { isolated } \\
\text { from } \\
\text { laboratory }\end{array}$} & \multicolumn{2}{|c|}{ Type species } \\
\hline & 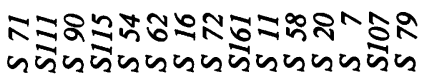 & & & & $\begin{array}{l}\text { B. licheni- } \\
\text { formis }\end{array}$ & B.lentus \\
\hline Motility & $+++++++++++++t$ & + & + & + & + & + \\
\hline Anaerobic growth in & & & & & & \\
\hline glucose broth & $++t+t+t+t-t+t+-$ & + & + & + & + & - \\
\hline Citrate utilization & $++t++t++-+++-$ & + & + & + & + & - \\
\hline Gelatin hydrolysis & $+++t+++t+t++t+t$ & + & + & + & + & - \\
\hline Casein hydrolysis & ++++++++-++++-+ & + & + & + & + & - \\
\hline Starch hydrolysis & $++t++t++t+t+-$ & + & + & + & + & + \\
\hline Glucose (acid) & ++++++++-+++- & - & + & + & + & - \\
\hline Arabinose (acid) & $++++++++-t+t-$ & - & + & + & + & - \\
\hline Mannitol (acid) & +++++++++-+-++- & - & + & + & + & - \\
\hline Indole & $----\cdots-\cdots-\cdots$ & - & - & - & - & - \\
\hline Voges-proskauer & +++-++++-+++++ & + & + & + & + & - \\
\hline Nitrate reduction & ++++++++++++++- & + & + & + & + & - \\
\hline Urease & ---+---++--++- & - & - & - & - & + \\
\hline Oxidase & $++++++t++t+t+$ & + & + & + & + & + \\
\hline
\end{tabular}


explanation undoubtedly applies to the well-known organism of Alexander-Jackson (1954; cf. also Livingston and Alexander-Jackson, 1970), which is described as passing from an L-form through a weakly acid-fast stage to a sporogenous stage, and which has now been shown to be identifiable with my own isolates.

Gram-positive sporing bacilli have been widely reported in the literature as occurring in the blood and tissues of healthy and diseased mammals (see Pease, 1967, 1970b for references), but of particular interest in this instance is the work of Roberts (1964), who isolated a bacterial L-form from outbreaks of synovitis in fowls, and identified it as Bacillus licheniformis, and also that of Benedek (1955), whose isolates, which he believed to be associated with human arthritis, appear from this description and photographs to be $B$. licheniformis. Since $B$. licheniformis is an unusually stable species of this variable genus, in its physiology (Bisset, personal communication), it is of interest to note that these, apparently parasitic, strains included several variant forms, whereas the saprophytic isolates, including those from this laboratory, were identical with the type strain in their reactions. It is also of interest that, serologically, the strongest reaction of the new, human isolates, was against the lentus variant. This suggests that they are, at least, not recent contaminants, but have developed separately from the normal, saprophytic strains of the species.

Even without the unusually long period of time that these L-form isolates require to establish themselves in primary culture, the bacteria are peculiarly liable to be overlooked. Such isolations are habitually treated with great reserve by bacteriologists, who are conditioned to disregard as contaminants any bacteria that show an unexpected ability to produce spores. Thus, it can be regarded as certain that, even if they were given time to develop, the majority of previous isolations have tended to be discarded, so soon as the bacteria had begun to revert to the stage at which they were recognizable as sporing bacilli. Since, however, there does exist a certain amount of independent evidence that $B$. licheniformis can be isolated from human beings, these observations should be repeated, as widely as possible, in order to evaluate the significance of the findings.

\section{Summary}

The bacterial L-forms, previously described as isolable from the blood and joint fluids of arthritic subjects, and also occurring in healthy persons, are identified, by morphology, physiology, and antigenic analysis as Bacillus licheniformis. Some strains are identical with the type cultures, and with new saprophytic isolates; some vary slightly in their physiological reactions, and may resemble the inactive lentus variant, with which both physiological types are more closely allied serologically.

The original isolates were usually in the L-phase and grew very slowly. On subculture they passed through a stage morphologically and antigenically resembling Listeria, and eventually reverted to recognizable sporogenous $B$. licheniformis: the process takes several weeks to complete.

This organism has been claimed by previous workers to be associated with arthritic conditions, but it is emphasized that further study is required.

I wish to thank Mrs. Roberta Bartlett and Miss Janice Green for practical assistance.

\section{References}

AleXANDER-JACKson, E. (1954) Growth, 18, 37 (A specific type of microorganism isolated from animal and human cancer: bacteriology of the organism)

BenedeK, T. (1955) 'Rheumatoid Arthritis and Psoriasis Vulgaris'. Edwards, Ann Arbor, Mich.

BisSet, K. A., AND StreEt, J. (1973) J. gen. Microbiol., 76, 369 (Morphological phases in the swarm of Bacillus licheniformis)

Cowan, S. T., AND Steel, K. J. (1965) 'Identification of Medical Bacteria', Appx. D, pp. 146-165. University Press, Cambridge

Duthie, J. J. R., STewart, S. M., AleXander, W. R. M., AND Dayhoff, R. E. (1967) Lancet, 1, 142 (Isolation of diphtheroid organisms from rheumatoid synovial membrane and fluid)

Livingston, V. W., and AleXander-Jackson, E. (1970) Ann. N.Y. Acad. Sci., 174, 636 (A specific type of organism cultivated from malignancy: bacteriology and proposed classification)

PeAse, P. (1967) Nature (Lond.), 215, 936 (Tolerated infection with the sub-bacterial phase of Listeria)

- (1969) Ann. rheum. Dis., 28, 270 (Bacterial L-forms in the blood and joint fluids of arthritic subjects) (1970a) Ibid., 29, 439 (Morphological appearances of a bacterial L-form growing in association with the erythrocytes of arthritic subjects)

- (1970b) Ann. N.Y. Acad. Sci., 174, 782 (Discussion: Microorganisms associated with malignancy)

—, Nicholls, L., AND STUART, M. R. (1972) J. gen. Microbiol., 73, 567 (Evidence that precipitin cross-reactions between Listeria, Erysipelothrix and Bacillus licheniformis are not due to the Rantz antigen)

RoBerTS, D. H. (1964) Res. vet. Sci., 5, 441 (L-phase bacterial forms associated with infectious synovitis in chickens and turkeys) 